$$
\begin{gathered}
\text { 성바오로 병원에 찾아온 환자중 임 상적으로 본 } \\
\text { 장기별 결핵분포 }(\text { 제 } 2 \text { 보 })^{\star} \\
\text { 가톨릭의대 내과학교실 } \\
\text { 한유식, 정진우, 박성학, 변해원 }
\end{gathered}
$$

$=$ Abstract $=$

\title{
A Clinical Study on Organ Distribution of Tuberculosis
}

\author{
Yu Sik Han, M. D., Jin Wu Jeong, M. D. Sung Hak Park, M. D. and \\ Hae Won Byun, M. D.
}

Department of Internal Medicine Catholic Medical College, Seoul, Korea

In order to evaluate the effect of B.C.G., we observed organ distribution of tuberculosis and the results were compared with the first report in 1970. We have studied 2,985 patients with tuberculosis diagnosed out of 193,514 patients seen at St. Paul's Hospital, Catholic Medical College, during the period of January, 1973 through August, 1977.

1) The rate of tuberculosis in this report is less $(1.54 \%)$ than first report $(2.3 \%)$

2) The peak of morbidity was in second decade and the sex ratio was $60 \%$ in man and $40 \%$ in female.

3) Pulmonary tuberculosis predominates all other forms with rate of $52.9 \%$ (male: $34.6 \%$, female: 18.3 $\%$ ), which was decreased from $67.8 \%$ in first report but the sex ratio were $2: 1$ in both studies.

4) Pulmonary tuberculosis combined with extrapulmonary tuberculosis was $18.6 \%$ in this report comparing with $5.7 \%$ in first report. There was no significant difference in prevalence of extrapulmonary tuberculosis compared between first and second report (26.5\% in first and $28.5 \%$ in second report).

5) Rates of minimal tuberculosis were $36.1 \%$ in this report and $26.6 \%$ in first report. Rates of far advanced tuberculosis were $12.5 \%$ in this report and $23.1 \%$ in first report.

6) Among extrapulmonary organs, the pleura was the most frequently combined with pulmonary tuberculosis. Rates of miliary tuberculosis combined with tuberculosis meningitis were $12.3 \%$ in this report and $5.5 \%$ in first report.

7) There was no signi:icant difference about the organ distribution in cases of extrapulmonary tuberculosis between first and second report.

^(본 논문은 가톨릭 중앙의료원 임 상의학 연구비 및 성바오로 병원의 연구비로 이루어진 것임) 


\section{서}

론

결핵에 대한 연구는 전 세계적으로 끊임없이 계속되어왔 으며 현대 의학의 발달과 사회 환경의 개선으로 치료와 관 리에 있어서 많은 발달을 가져왔다. 그러나 결핵은 구미 에 비해 우리 나라는 아직도 많은 율-의 발생과 사망원인 이 되고 있는 중요한 보건 문제임은 재론할 여지가없으 며 다른 어느 질병보다도 합리적으로 해결되어야 할 질 환이라고 생 각된다.

1965 년과 1970년 2 차에 걸쳐 시행된 전국 결핵 실태조 사"의 결과 엑스선상 활동성결핵의 유병 윢과 균양성 결핵 의 유병율은 각각 1965 년에 $5.1 \%$ 와 $0.94 \%, 1970$ 년에 $4.2 \%$ 와 $0.74 \%, 1975$ 년은 $3.3 \%$ 및 $0.76 \%$ 로 보고되어 차츰 감소되고 있는 것으로 나타났다. 그러나 결핵의 동 태, 특히 BCG의 효과를 평가하는 한 방법으로 폐외 장기 결핵의 동태를 알기위하여 결핵의 장기별 분포와 그 역학적 조사의 필요성에 따라 1970년의제 1 차 ${ }^{2}$ 보고를 한 바 있거니와 1973년 부터 1978년 까지의 결핵의 장기별 이환-율-을 조사하여 1960 년 대와 1970년대의조사를 비교분 석함으로서 그동안의 변화를 관찰하여 다음과 같은 결과 를 얻었기에 이에 보고하는 바이다.

\section{관찰대상 및 방법}

1973년 1 월 1 일부터 1978년 8 월 31 일까지 가톨릭의 과대학 부속 성바오로병원 각 과를 찾아온 환자 193,514 명중에서 방사선소견, 객담배양 수술시 육안소견, 병 소의 삼출물검사 및 배양, 병리조직학적 소견등으로 진 단된 결핵환자 2985 명을 대상으로 폐결핵 만을 가진 경우 폐결핵과 폐외 장기결핵이 합병된 경우와 폐결핵은 없이 폐외 장기에만 결핵을 가진 경우를 분류하여 결핵의 각 장기별 이환율을 관찰하고 아울러 결핵의 남녀별, 연령별 분포상황을 관찰하였다. 또한 위의 결과를.저자등이 1963 년 1 월 1 일부터 1968년 8월 31일까지 조사하여보고한 바 있는 1 차보고의 결과와 비교 분석하였다.

\section{관찰성적}

\section{1 ) 결핵의 유병율 및 연령별 빈도}

1963 년부터 1968 년까지 총환자 183,915 명중 결핵환자 는 4,212명으로 그 빈도는 $2.3 \%$ 였던 반면 1973년부터 1978 년까지의 총 환자 193,514 명중 결핵환자는 2,985 명 으로 그 빈도는 $1.54 \%$ 이었다. (Table 1) 연령별로 본빈
Table 1. Prevalence of Tuberculosis in St. Paul's Hospital

\begin{tabular}{lll}
\hline \hline Duration & $\begin{array}{l}\text { No. of } \\
\text { Patients }\end{array}$ & $\begin{array}{c}\text { No. of } \\
\text { Tubzrculosis pt. }\end{array}$ \\
\hline $63-68$ & 183,915 & $4,212(2.3)$ \\
$73-78$ & 193,514 & $2,985(1.54)$ \\
\hline
\end{tabular}

도는 1960 년대의 경우 25 29세 사이가 전체 의 $15.2 \%$ 로 가장 많았으며 20 24세, 30 34세 사이가 각각 $13.3 \%$ 였는데 1970년대는 20 24세사이 가 전체 의 $13.0 \%$ 로 가 장 높은 빈도를 나타냈으며 그 다음은 25 29세의 $11.8 \%$ $30 \sim 24$ 세의 $10.9 \%$ 순이었다. (Fig 1)

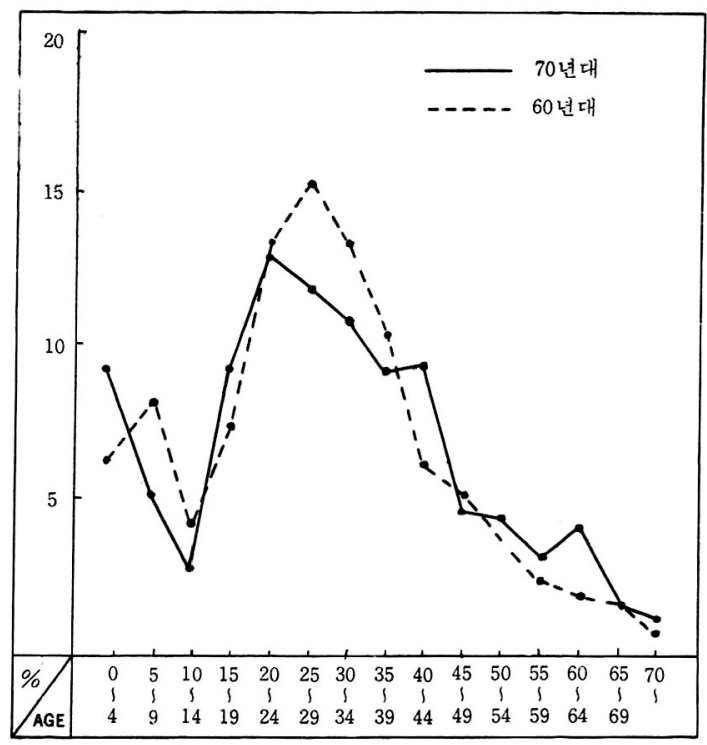

Fig. 1. Age \& Sex Incidence

\section{2) 장기별 분포}

전체 2,985 명의 결핵양상을 분석해 본 결과 폐결핵 단 독으로 있는 예 가 $52.9 \%$ 로 남자가 $34.6 \%$, 여자가 $18.3 \%$ 로 남자에서 약 2 배가량 많았다. 폐외 결핵만 있는 경 우는 $28.5 \%$ 로 남녀의 사이는 유의한 차이가 없었다. 폐 결핵과 폐외 결핵이 합병한 예는 $18.6 \%$ 로 남자가 $10.0 \%$, 여자가 $8.6 \%$ 이었다. (Table 2)

Table 2. Prevalence of Type of Tuberculosis

\begin{tabular}{ccccc}
\hline \hline & \multicolumn{2}{l}{ Pul. Tbc } & \multicolumn{3}{l}{ Combined Extrapul. } & Total $(\%)$ \\
Sex & only & Tbc. & Tbc. only & \\
\hline M & $1033(34.6)$ & $298(10.0)$ & $460(15.4)$ & $1791(60.0)$ \\
F & $546(18.3)$ & $257(8.6)$ & $391(13.1)$ & $1194(40.0)$ \\
Total & $1579(52.9)$ & $555(18.6)$ & $851(28.5)$ & $2985(100)$ \\
\hline
\end{tabular}




\section{3) 폐결핵의 분류}

폐결핵의 경우 1960 년 대에는 3,118 명, 1970 년 대에 는 2, 273 명이었는데 각 정도별로 분류해 본 결과 1960년대 는 중둥증결핵 842 명 $(27 \%)$ 으로 가장 많은 양상을 보였으 며, 1970 년 대에는 경증 결핵 820 명 (36.1\%)으로 가장 많 았다. 1960 년대 보다 1970년대에서 경증 폐결핵은 증가 하였고 $(\mathrm{P}\langle 0.01)$, 중증 폐결핵은 통계적으로 의의있게 감 소하였다. $(\mathrm{P}\langle 0.01) \quad$ (Fig. 2)

\section{s}

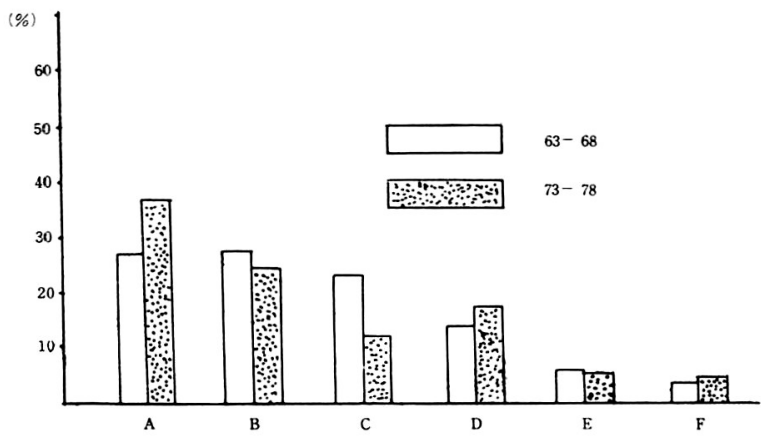

Fig. 2. Prevalence of Pulmonary Tuberculosis in First and Second Observation
A : Minimal Tbc
B : Moderate Tbc
C : Far advanced
D : Unclassified
E : Primary
F : Miliary Tbc

\section{4) 폐외 결핵을 합병한 폐결핵의 빈도}

폐결핵과 폐외장기의 결핵을 합병한 경우는 1960 년대 에는 총결핵환자 4,212 명중 237 명으로 $5.7 \%$ 였으며 1970 년대에는 2,985 명중 555 명으로 $18.6 \%$ 였다. 폐외에 침범 된 장기를 보면 1960년대와 1970년대 모두 늑막이 각각 $41.8 \%, 43.3 \%$ 로 가장 많었으나 그 외 장기로는 1960 년 대에 임파절, 복막, 뇌막의 결핵순서로 닪은 반면, 1970 년대에는 복막의 결핵이 증가되며 속립성 결핵과 뇌막염 을 합병한 증예가 많었다. (P<0.01) (Fig. 3)

\section{5) 폐외 결핵의 장기별 분포 비교}

폐를 침범하지 않고 폐외 장기에 만 단독으로 결핵을 가 진 경우는 1960 년대에 총결핵환자 4,212 명 중 1.124 명으로 $26.5 \%$ 이 었고 1970 년 대는 2.985 명 중 851 명으로 $28.5 \%$ 로 비숫했으며 이 중에서 골관절결핵이 1960 년대와 1970 년 대에 각각 $23.8 \%, \quad 31.8 \%$ 로 가장 많었으며 그 다음으 로는 1960 년대에는 임파절결핵, 늑막염, 복막염이 22.5 $\%, 21.3 \%, 12.5 \%$ 의 순서이었으며 1970 년대에는 임파절 결 핵, 뇌 막염, 늑막염 의순서로 각각 $20.6 \%, 19.7 \%, 13.1$ $\%$ 로나타남으로 복막염의 경우는 감소하는 양상을 보였 으나 속립결핵의 경우는 상당히 증가되어 있었다. ( $\mathrm{P}<0.05)$ 또 이비인후과 기관의 결핵이 감소한 반면 결핵 성심낭 염의 경우는 1970 년대에 증가되는 추세를 볼 수 있었다. (Fig. 4)

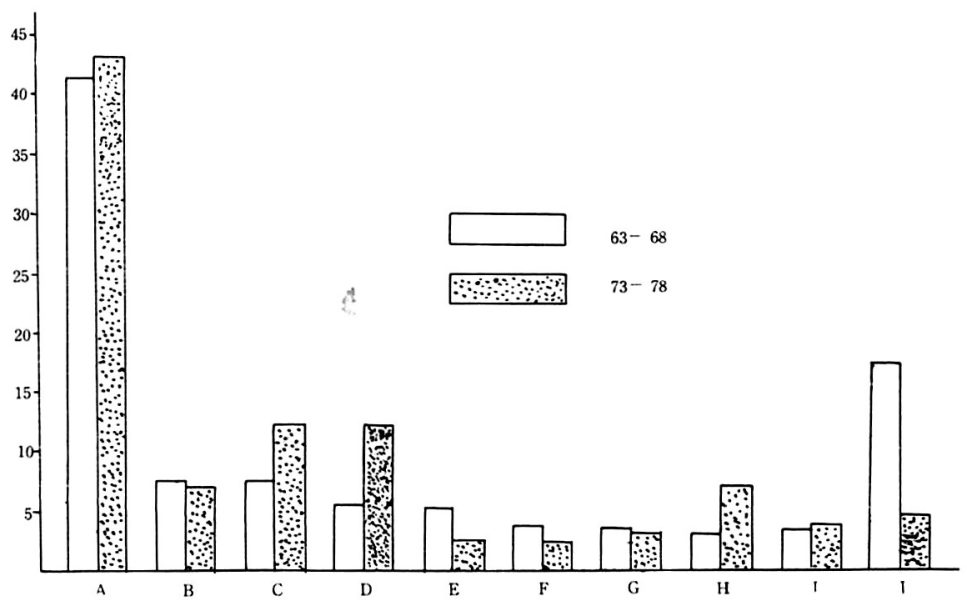

Fig. 3. Prevalence of Pulmonary Tuberculosis combined with Extrapulmonary Organs in First and Second Observation
Lung and $\mathrm{A}$ : Pleura
B : Lymphnode
C : Peritoneum
D : Miliary Tbc.
$\mathrm{E}$ : Bone \& Joint
$\mathrm{F}$ : Intestine
$\mathrm{G}:$ Larynx
$\mathrm{H}:$ Kidney
I : Meninges
$\mathrm{J}:$ Others
(* Miliary and Meninges) 


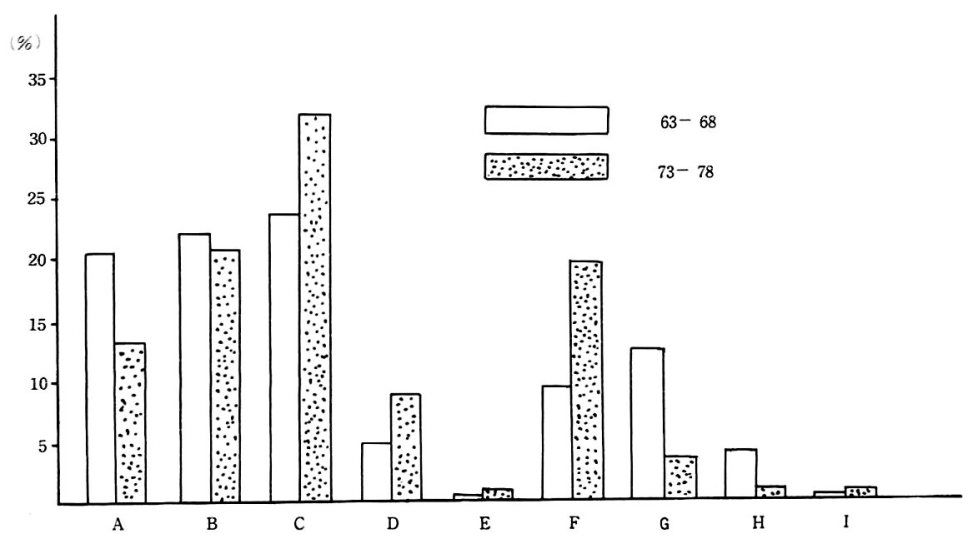

Fig. 4. Prevalence of Organ Distribution of Extrapulmonary Tuberculois Only in First and Second Observation
A : Pleura
B : Lymph node
$C:$ Bone and Joint
D : G-U Tract
$\mathrm{E}: \mathrm{Gy}$. Organ
$\mathrm{F}:$ Meninges
G : Abdominal Cavity
H : E. N.T.
I : Pericardium

\section{6) 결핵의 장기별 이환율 비교}

결핵이 어느 장기에 단독 또는 합병하여 침범한 것은 관여하지 않고 각 장기별로 결핵이 침범된 결핵 자체의 각장기별 이환율을 비교해 보면 1960년대는 폐를 침범 한 예가 $63.3 \%$ 로 가장 많았고 그 외 늑막에 $7.7 \%$, 골 관절에 $6.3 \%$, 임파결절에 $6.1 \%$, 복강내에 $4.7 \%$, 되 막염이 $2.9 \%$, 속립성 결핵이 $2.3 \%$, 그외 비뇨생 식기등
혈행성 만연에 의한 폐외장기의 결핵도 많은 윢이었는 데 1970 년대 역시 가장 많이 침범되는 장기는 폐로 전체의 $57 \%$, 그 다음은 늑막염이 $10.5 \%$, 골관절 $7.9 \%$, 뇌막 염 $6.1 \%$, 임파절 $5.5 \%$, 복강내결핵 $3.9 \%$ 등의 순서로 나타남으로써 1960년대보다 1970년대는 폐, 임파절, 복 강내결핵이 감소한 반면 늑막, 뇌막, 신장, 골 관절등의 결핵 은 증가되는 양상을 나타내었다. (Fig. 5)

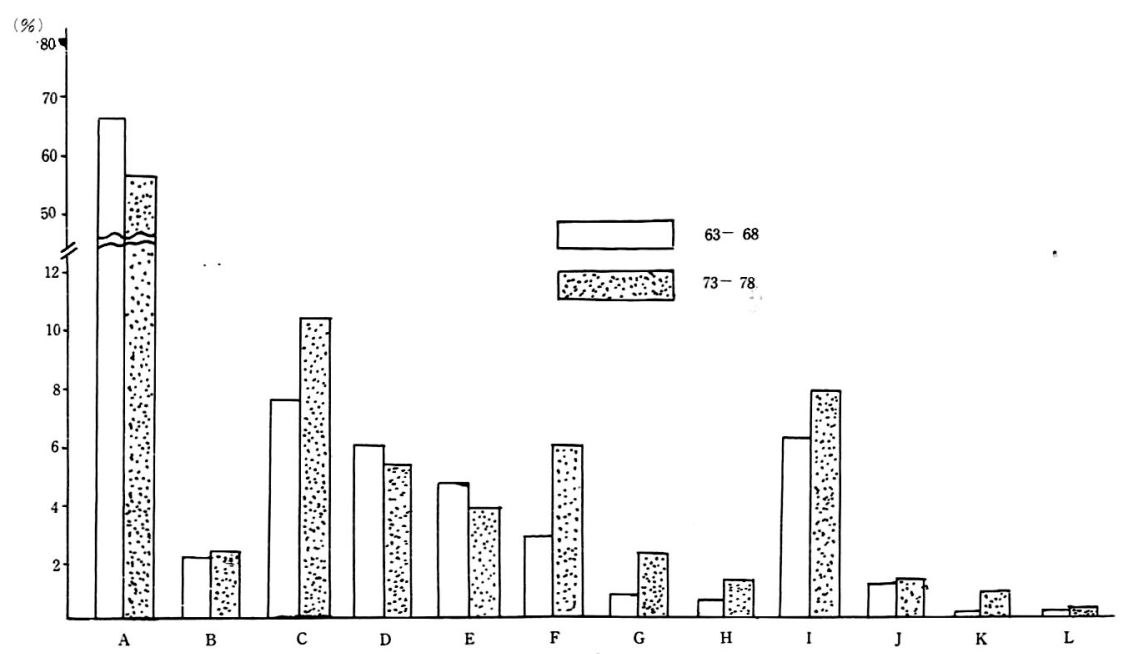

Fig. 5. Prevalence of Organ Distribution of Tuberculosis in First and Second Observation
A : Pulmonary Tbc
B : Miliary Tbc
$C:$ Pleurisy
D : Lymphnode
E : Abdominal Cavity
$\mathrm{F}:$ Meninges
G : Kidney
$\mathrm{H}:$ Epididymis
I : Bone and Joint
J : Larynx \& Pharynx
$\mathrm{K}$
$\mathrm{K}$ : Pericardium
L : Gy. Organ 


\section{고}

안

결 핵은 해결되어야 할 우리나라의 여러가지 보건문제 중에 서 가장 긴급을 요하는 문제임은 더말할 필요가 없 을 것이다. 우리나라의 결핵 실태는 보건사회부와 대한 결핵 협회에서 실시한 전국 결핵 실태조사에서 보면 엑스 선 상 폐결핵 유병 윤 은 1975 년에 $3.3 \%$ 로 1970 년의 $4.2 \%$,

1965 년의 $5.1 \%$ 에 비하여 통계적으로 유의하게 감소되고 있는 것으로 나타나 있다. 그러나 결핵이라 하면 일반 사회의 인식이 우선 폐결핵만을 생각하게 되나 폐외 각 장기의 결핵도 상당허 많으며 이에 대한 관리와 치료도 중요한 의미를 갖는다. 따라서 켸결핵뿐만 아니라 켸외 장기의 결핵분포도와 그 역학적 조사를 동해 널리 인식 시키고 관리되어야 할 것이다. 1975년도에도 우리나라 폐 결핵에 대해서는 결핵관리사업에 필요하고도 중요한 기준이 될만큼 세밀히 조사된 바 있었으나 폐외각 장기 별 분포와 그 역학적 조사에 대해서는 저자들이 1970년 에 가톨릭 의과대학 부속 성바오로병원에서 1963년부터 1968 년까지 내원한 환자를 대상으로 조사하여 보고한후 아직까지 더 자세한 보고는 없는 것으로 되어있다. 외국 의 경우는 Stradling ${ }^{3)}$ 등이 다른 지방 (Irland, British. Caribean, Africa, India, Parkistan, Rest of Europe and Rest of Asia)으로부터 England 와 Wales 지방에 이주한 이주민과 Great Britisch원주민 간 결핵의 이 환육을 장기 별로 세분하여 보고하였다.

Miller ${ }^{4)}$ 등은 1968년 비선택적으로 Kenja의 11개 지방 에서 결핵으로 진단된 1,296 명을 대상으로 각 장기별 로 구분하여 이환윢을 보고하였다.

연자들의 경우에는 결핵의 유병 윰은 1960년대 양상이 연령이 증가함에 따라 증가하여 25 29세군에서 $7.6 \%$ 를 상회하여 점차 감소하였고, 전반적으로 남자가 여자 보다 고윰이었으며, 1970년대는 20 24세 군에서 가장 높았으며 그 절정기는 1960년대에 비해 낮았다. 이와같 이 결핵은 주로 15 39세의 청장년기에 많았다. 각 장기 별 분포를 보면 켸결핵만 가지고 있는 경우는 Stradling $86.5 \%$, Miller $89.8 \%$ 로 결핵 환자중에서 가장 많았 고 연자들이 조사한 1960 년 대 $67.8 \%, 1970$ 년 대 $52.9 \%$ 보다 높았다.

1965 년 결핵실태조사에 의하면, 경증결핵 $3.3 \%$, 로 보고된 바 있고, 1975 년에는 $2.2 \%, 0.8 \%, 0.3 \%$ 로 나타났으나 저자들의 통계는 병원에 찾아온 환자들이었 으므로 중증결핵이 많을 것으로 생각된다. 그러나 1960 년대와 1970년대를 비교해보면 확실히 경증결핵은 증가
되고 중증결핵은 감소되는 것으로 나타나는데 이는 생활 수준이나 위생상태의 향상, 결핵에 대한 인식과 교육으 로 초기에 치료받는 사람이 늘고 항결핵 화학요법제 등 의 발달로 중증결핵까지 진전되는 예가 감소되는 것으로 추측된다.

폐결핵과 켸외장기의 결핵을 합병한 경우에 Stradling 과 Miller 는 확실히 구분하여 제시한 바 없었으나 저자들 은 1970 년에 237 예를 각 장기별로 분류를 하여 기술한 바 있고 이번 1970년대의 결과와 비교해 보면 폐다 늑 막을 합병한 경우가 가장 많았고 속립성 결핵과 뇌 막염 을 합병한 예가 증가되는 양상을 보인 것은 Steven5) (1974), Suguro')(1973) 등이 지적한 바와 같이 오랫동 안 항암제, 부신피질호르몬제 또는 면역억제제의 사용이 많아지고 특히 노인에서 그 발병윢이 높아지는 것으로 추측하게 한다. 켸외 장기에 만 결핵을 가진 환자에서 임 파절결핵은 Stradling $34.1 \%$, Miller $34.8 \%$ 로 많았 다고 했으나, 저자들은 1960 년대에 $22.5 \%, 1970$ 년대 에 $20.6 \%$ 로 별 차이가 없었고 늑막염이 $21.3 \%$ 에서 $13.1 \%$, 복강내결핵이 $12.5 \%$ 에서 $3.7 \%$ 로 감소된 반 면 골관절결핵이 $23.8 \%$ 에서 $31.8 \%$ 로 뇌막염이 9.1 $\%$ 에서 $9.7 \%$ 로 증가된 것으로 나타났다.

골관절결핵에 대해 Miller 는 21\%, Stradling 은 7.5 $\%$ 의 차이를 보이고 있고 늑막염에 대해서는 Miller 는 $15 \%$ 로 저자들의 경우 1970 년대 $13.1 \%$ 와 비숫했다. 결국 폐외장기에만 결핵을 가진 경우는 대체로 골관절, 임파절, 뇌막염, 늑막염 및 비노생식기계통의 결핵이 많 았으며 이와같은 각 장기별 결핵의 분포 양상의 변화는 앞으로도 계속 추적 검사로 분석하여야 할 과제일 것이 다.

\section{결 론}

결핵의 각 장기별 분포와 그 역학적조사 및 시간경과 에 따른 변천과정을 알아보기 위하여 1973년 1 월 1 일 부터 1978년 8 월 31 일까지 가톨릭의가대학 부속 성바 오로병원 각 과에 찾아온 총환자 195,514 명중 결핵으 로 진단된 2, 985 명을 대상으로 각 장기별로 분류하여 1963 년부터 1968년까지 시행해서 1970년에 발표. 한 1 차 보고와 비교분석하여 다음과 같은 결과를 얻었다.

1) 병원에 온 총환자중 결핵환자는 1960 년대에 $2.3 \%$ 에 비해 1970 년대는 $1.54 \%$ 로 적은 양상을 보였다.

2 ) 총 결핵환자의 성별비교는 1960 년대에 남자 59.5 $\%$, 여자 $40.5 \%$ 였으며, 1970 년대는 남자 $60.0 \%$, 여 자 $40.0 \%$ 로 비숫했으며, 연렁별로는 1960 년대와 1970 
년대 모두 20 30대에서 가장 많았으나 1970년대가 1960 년대보다 약간 적었다.

3 ) 폐결핵 만을 가진 환자는 남자가 1960 년대에 44.1 $\%, 1970$ 년대에는 $34.6 \%$ 이고 여자는 1960 년대에 23.7 $\%, 1970$ 년대에 $18.3 \%$ 로 1970 년대에 적었으나 남녀의 비는 약 $2: 1$ 정도로 같았다.

폐결핵과 폐의 장기의 결핵을 합병한 경우는 1960 년 대에 $5.7 \%, 1970$ 년대에 $18.6 \%$ 로 1970 년대에 현저히 많았고 폐의 장기에 만 결핵을 가진 경우는 전 결핵 환자 의 $26.5 \%, 28.5 \%$ 로 별 변화가 없었다. 이둘의 남녀 의 비는 거의 비슷했다.

4 ) 폐결핵 만 가진 환자의 경우는 경증결핵이 $26.6 \%$ 에서 $36.1 \%$ 로 많아졌고 중증결핵은 $23.1 \%$ 에서 12.5 $\%$ 로 적었다.

5 ) 폐결핵과 폐외 결핵을 합병한 경우는 폐와 늑막의 합병이 가장 많았으며 속립성결핵과 뇌막염의 합병이 현 저히 많았다.

6 ) 폐외 장기에만 결핵을 가진 환자중에서 늑막, 복 막, 이비인후과결핵이 적은 반면 골관절, 뇌막, 비뇨생 식기계통의 결핵이 많았다.

7 ) 각 장기별 결핵 이환율 분포를 보면 폐결핵이 단 연 많았고 뇌막, 비노생식기계통의 결핵과 결핵성 심낭 얺이 1960 년대보다 많았다.

결론적으로 B. C. G.의 호과는 특별이 반영되고 있는 것 같지는 않으며 1960 년대와 1970 년대에는 특별한 차이 가 없었다.

\section{References}

1. 대한민국 결 핵실태 조사결과 : 보건사희부, 대한결 핵협회 1966년, 1970년, 1975년.

2. 이광현, 원언식, 기춘석, 최응규, 변해원 : 성바오로 병 원에 찾아온 환자중 임 상적으로 본 장기별 결핵분포 결핵 및 호훕기질환 $41: 11,1970$

3. Stradling P.: Tuberculosis among immigrants to England and Wales. Tubercle 47;145, 1966

4. Miller A. B.: A National sampling survey of Drug Resistance and other Factors. Tuberculosis in Kenya: An East Africa and British Medical Research Council Co-operative Invetigation. Tubercle Lon. 49;136, 1968

5. Sahn S. A., Neff T. A., : Miliary Tuberculosis. Am J Med 56;495, 1974.

6. Cho Suguro: Clinical epidemiology of adult miliary tuberculosis in recent years. Kekkaku 48;369, 1973 